\title{
Unilateral phrenic nerve stimulation for neurogenic hypoventilation in Arnold Chiari malformation
}

\author{
Nitin Garg \\ Department of Neurosurgery, Bhopal Memorial Hospital and Research Centre, Bhopal, Madhya Pradesh, India
}

\section{A B S T R A C T}

Long- term ventilator dependence in patients with neurogenic hypoventilation is associated with significant morbidity and restricts mobility. Diaphragmatic pacing by phrenic nerve stimulation (PNS) is a viable alternative. This is a case report of patient with Arnold-Chiari malformation with extensive syrinx who had neurogenic hypoventilation during sleep even after foramen magnum decompression and resolution of the syrinx. Unilateral PNS was done using spinal cord stimulator. With intermittent stimulation for $8 \mathrm{~h}$ while asleep, patient could be weaned off the ventilator completely. At 2 years follow- up, patient is ambulant and has returned to his routine activities. PNS is a good treatment tool in patients with neurogenic hypoventilation. Spinal cord stimulator can be used with optimal results. This is first such reported case of using spinal cord stimulator for PNS from India.

Key words: Arnold-Chiari malformation, diaphragmatic stimulation, neurogenic hypoventilation, phrenic nerve stimulation, sleep apnoea, spinal cord stimulator

\section{INTRODUCTION}

Neurogenic hypoventilation can result from various disorders affecting the brainstem and high cervical cord. Prolonged ventilator dependence causes significant morbidity, prolongs hospital stay, restricts mobility and limits ability to return to routine activities. Phrenic nerve stimulation (PNS) for diaphragmatic pacing is a viable therapeutic alternative for these patients.

The specific device for phrenic nerve pacing (by Avery Biomedical Devices, USA) is not available in many countries including India. To overcome this, Taira first described the use of spinal cord stimulator for diaphragmatic pacing in 2003 with good results, ${ }^{[1]}$ reproduced subsequently by others. ${ }^{[2-4]}$ We describe the use of this device in a case of central neurogenic hypoventilation. To the best of our knowledge, this is first such case of PNS using the spinal cord stimulator in India.

\begin{tabular}{|l|l|}
\hline \multicolumn{2}{|c|}{ Access this article online } \\
\hline Quick Response Code: & Website: \\
\hline & www.ijns.in \\
\cline { 2 - 3 } & \\
\hline
\end{tabular}

\section{CASE REPORT}

A 25-year-old patient presented with progressive quadriparesis of 2 months duration with shallow breathing. Magnetic resonance imaging (MRI) was suggestive of Arnold-Chiari malformation type I with extensive syringomyelia and bulbia [Figure 1]. Foramen magnum decompression with duraplasty was performed. Post-operatively, neurological recovery was uneventful except for prolonged ventilator support and delayed weaning over 2 weeks. At the time of discharge, patient was ambulant with support, breathing spontaneously with normal arterial blood gas (ABG) results.

Patient was readmitted to the emergency department after 1 month with a history of seizures, altered sensorium of few hours' duration and shallow breathing. His ABG was suggestive of severe respiratory acidosis $\left(\mathrm{pCO}_{2} 91 \mathrm{mmHg}\right.$, $\mathrm{pO}_{2} 71.2 \mathrm{mmHg}, \mathrm{pH}$ 7.012). Following elective ventilation, the blood gases were normalized and patient regained sensorium. Detailed history given by relatives suggested very few respiratory movements during sleep with progressive drowsiness during daytime and gradual unconsciousness. A repeat MRI revealed complete resolution of syrinx with decompressed foramen magnum [Figure 2]. Tracheostomy was performed to facilitate early weaning. Continuous monitoring revealed a trend of significant reduction in respiratory rate, progressive buildup of end-tidal $\mathrm{CO}_{2}$ and deterioration of blood gases during sleep, which

Address for correspondence: Dr. Nitin Garg,

Department of Neurosurgery, Bhopal Memorial Hospital and Research Centre, Bhopal - 462 038, Madhya Pradesh, India.

E-mail: drnitingarg@hotmail.com 
improved remarkably during awake state [Figure 3]. These findings were suggestive of central neurogenic hypoventilation $(\mathrm{CNH})$ (Ondine's curse). In spite of prolonged conservative efforts as breathing and isometric exercises, invasive ventilation was required intermittently for 1-2 days after 5-6 days of spontaneous breathing due to the progressive buildup of $\mathrm{pCO}_{2}$, with symptoms of hypercarbia [Figure 3]. Similar trend continued for 5 months with no significant improvement in the duration of intermittent ventilation. At this stage, with no further progress, the options of home based intermittent ventilator support and diaphragmatic pacing by PNS were considered.

The patient and his family opted for PNS considering

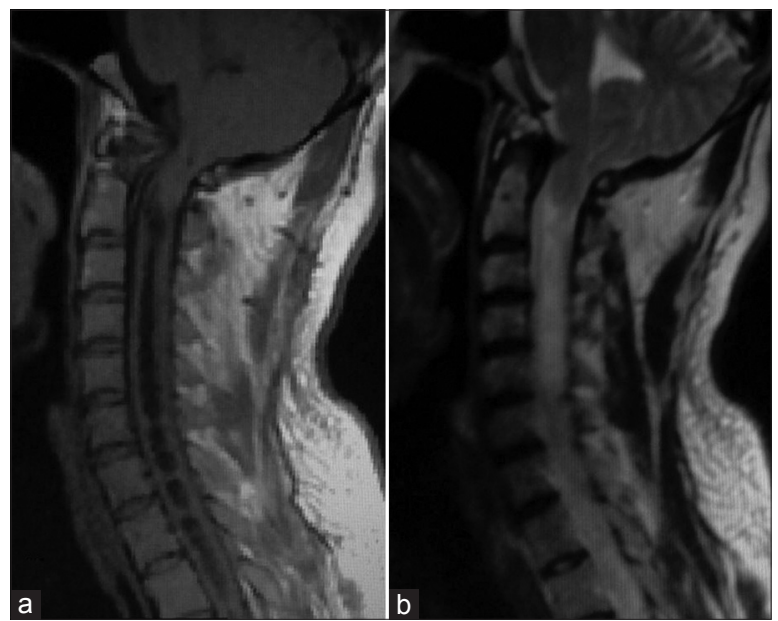

Figure 1: Pre-operative MRI scan - tonsillar herniation with extensive syrinx. (a) T1-weighted (T1W) sagittal image. (b) T2W Sagittal image benefits in terms of long- term costs, morbidity and mobility.

\section{Procedure}

Spinal cord stimulator (Synergy, Medtronics Inc., USA) used for pain management was used, as the specific device for PNS is not available in India. As this is an off-label indication, the patient and the family provided informed consent for PNS using the spinal cord stimulator. The phrenic nerve was exposed and stimulated in the neck along the posterior border of sternomastoid muscle [Figure 4] and connected to the pacemaker (Medtronics Synergy) in infraclavicular pocket. Considering that stimulation would be required during sleep only (about 8-9 h), unilateral stimulation of phrenic nerve was thought to be feasible. Same pacemaker can be used to connect another lead for stimulating the other phrenic nerve if unilateral stimulation resulted in suboptimal outcome.

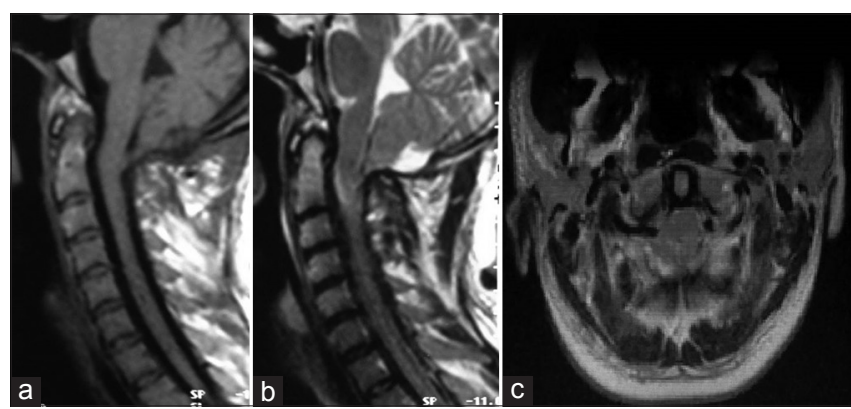

Figure 2: Post-operative MRI scan - resolution of syrinx with decompressed foramen magnum. (a) T1-weighted (T1W) sagittal image. (b) T2W sagittal image. (c) T2W axial image at $\mathrm{C} 1$ with cervicomedullary junction decompressed
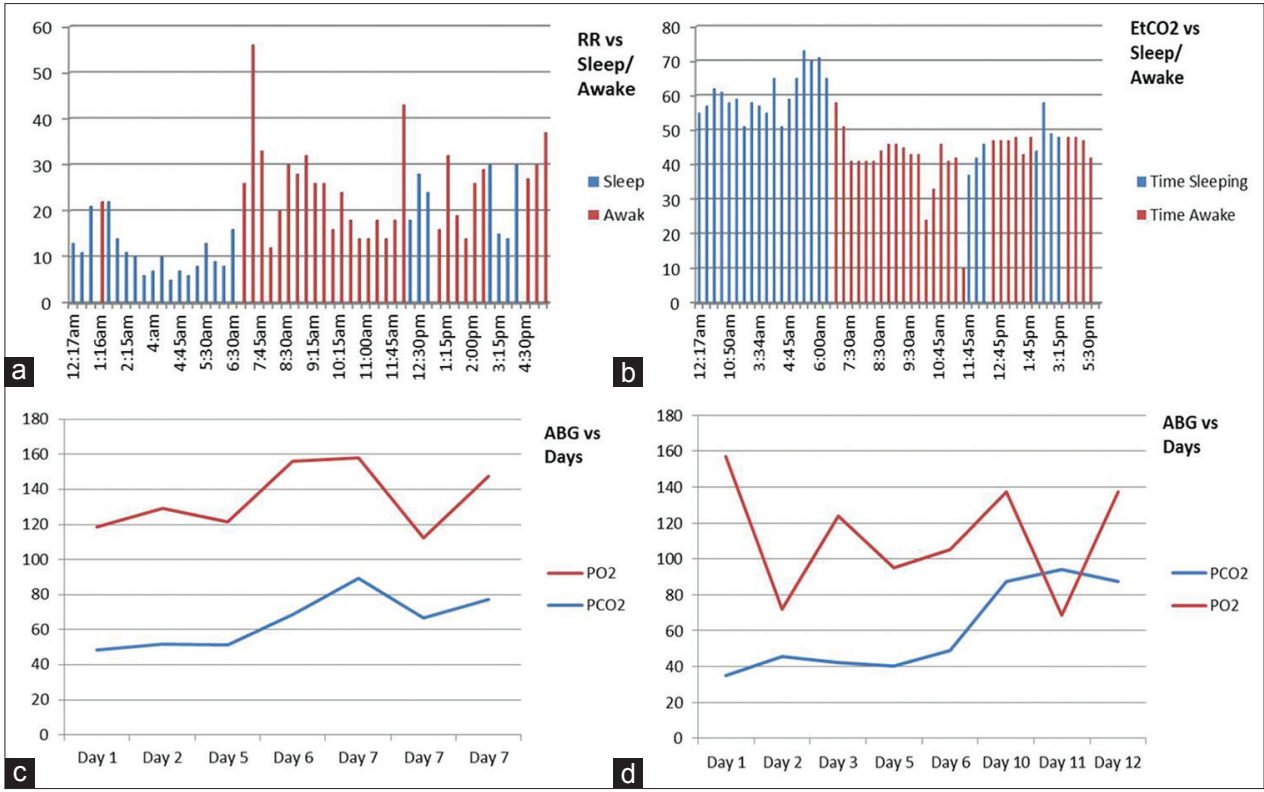

Figure 3: Trend of respiratory rate, end-tidal $\mathrm{CO} 2, \mathrm{pO} 2$ and pCO2. (a) Respiratory rate variation with sleeping and while awake. (b) Variation in EtCO2 with sleep-awake cycle. (c, d) Trend of pO2 and pCO2 over days in two separate months 


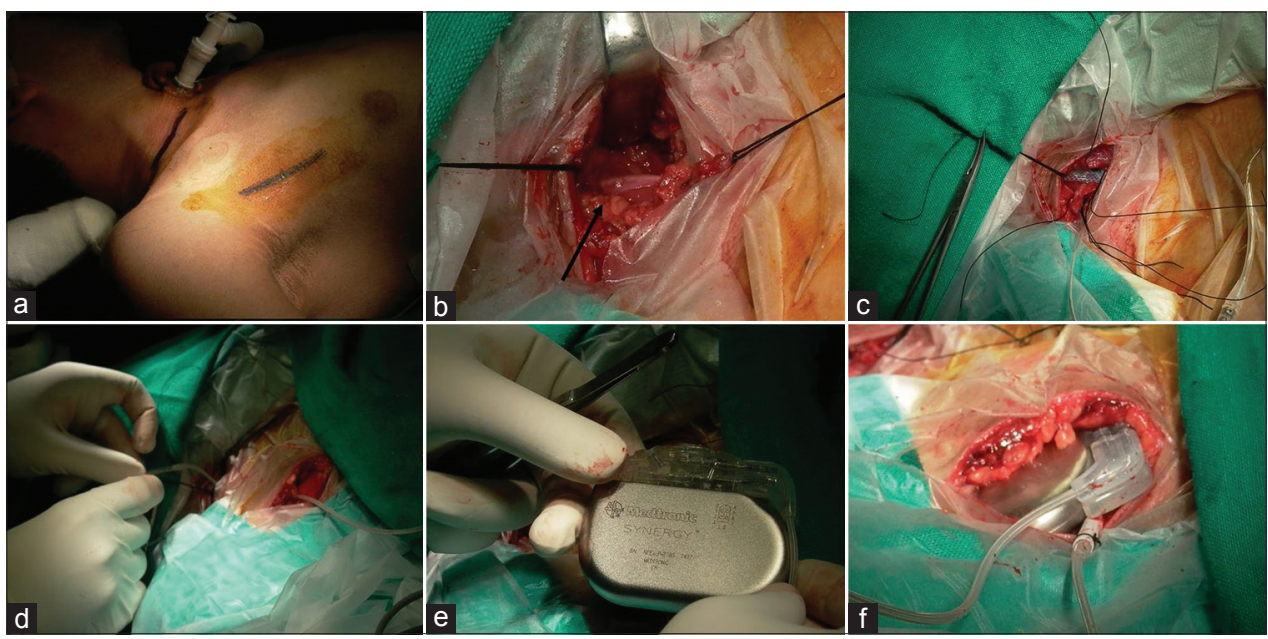

Figure 4: Intra-operative images. (a) Planned incisions (in the neck and infraclavicular pocket). (b) Phrenic nerve exposed (arrow). (c) 4-lead electrode placed in contact with phrenic nerve and fixed with non-absorbable silk suture. (d) The lead being tunneled from neck to subclavicular pocket. (e) Stimulator used for the procedure. (f) Pacemaker placed in subclavicular pocket.

Post-operatively, the patient was gradually weaned off the ventilator. Post-operative radiograph confirmed proper position of the lead [Figure 5]. The stimulation was initially started for $4 \mathrm{~h}$ in the afternoon and $8 \mathrm{~h}$ in the night with no stimulation in between these two cycles in accordance with the sleep pattern during the day and night and to avoid fatigue of the phrenic nerve due to prolonged continuous stimulation. The device was set in cyclic mode (on $2 \mathrm{~s}$, off $3 \mathrm{~s}$, soft start $1 \mathrm{~s}$ ) to maintain respiratory rate of 12 breaths per min. The amplitude was kept at $1.8 \mathrm{mV}$, pulse width $120 \mu$ s and frequency of $25 \mathrm{~Hz}$. The pulse width and frequency were almost similar to the previous reports, ${ }^{[1,2]}$ but the amplitude was much less than mentioned in these cases. Starting empirically from $1.5 \mathrm{mV}$, the diaphragmatic contractions were adequate to maintain sufficient tidal volume at $1.8 \mathrm{mV}$. Beyond $1.9 \mathrm{mV}$, there was significant discomfort in the form of sudden and painful jerky contraction of the diaphragm and referred pain to the shoulder. Intact diaphragmatic conditioning could be the explanation for lower voltage requirement.

Gradually, the daytime stimulation was turned off and night-time stimulation for $8 \mathrm{~h}$ continued. With no ventilator support required for a month and normalized respiratory parameters (respiratory rate, $\mathrm{EtCO}_{2}$ and $\mathrm{pCO}_{2}$ ), the tracheostomy was closed and patient discharged. Follow-up with weekly blood gases over the next 6 weeks remained normal (mean $\mathrm{pCO}_{2}-29.94 \mathrm{mmHg}$ ). Presently, at 2 years, he remains completely off the ventilator, with no changes required in the settings and duration of stimulation.

The battery has a limited life depending upon the usage. As only single lead is being used intermittently, the minimum battery life would be around 5-6 years.

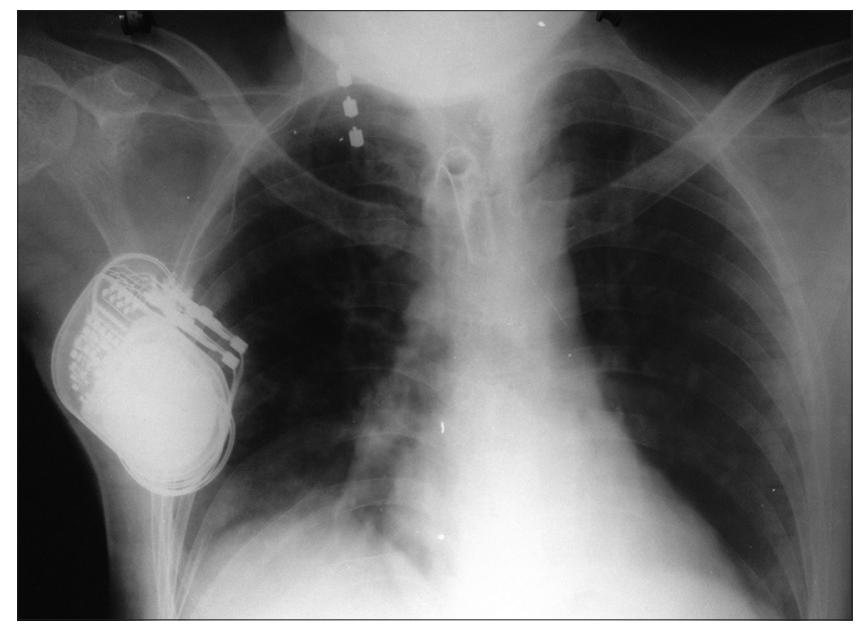

Figure 5: Post-operative chest X-ray with lead and pacemaker

To avoid unexpected failure of the battery, various stimulation and battery parameters (voltage) will be monitored every 6 months by the $\mathrm{N}$-vision programmer (Medtronics Inc., USA). If the voltage falls below $2.4 \mathrm{~V}$, the battery needs to be replaced. Presently, this value is 3.12 .

\section{DISCUSSION}

Electrophrenic respiration was first described by Sarnoff, an electrophysiologist and pioneered by Glenn, a surgeon who renamed this as diaphragmatic pacing. ${ }^{[3]}$

The major indications for diaphragmatic pacing are central alveolar hypoventilation (CAH) and quadriplegia due to high cervical cord lesions. ${ }^{[4-6]}$ Although quadriplegic patients with diaphragmatic paralysis require full-time support, those with $\mathrm{CAH}$ require this only during sleep when their hypoventilation becomes more apparent, 
the "Ondine's curse". ${ }^{[7]} \mathrm{CAH}$ could be congenital affecting newborns in most severe form to children at later stages or could be acquired secondary to different pathological conditions such as tumors, demyelination, meningoencephalitis, stroke, vascular malformation and syringobulbia affecting the respiratory centers. ${ }^{[4]}$

The electrode can be implanted on the phrenic nerve at various regions as in the neck, in the thorax by a thoracotomy or video assisted thoracoscopic surgery ${ }^{[5]}$ or on the diaphragm via laparotomy or laparoscopically. ${ }^{[8]}$ In the present case, phrenic nerve was stimulated in the neck similar to the method described by Taira. ${ }^{[1]}$ The access is relatively easy with no significant procedure related morbidity.

Depending upon the severity of neurogenic hypoventilation, patients may require bilateral/unilateral PNS and continuous versus intermittent pacing mainly while asleep. ${ }^{[9]}$ Unilateral PNS during sleep was adequate in the presented case due to sleep apnea.

In a non-randomized trial comparing mechanical ventilation and PNS of 64 patients of spinal cord injury, Hirschfeld et al. ${ }^{[10]}$ noted that though the initial cost for PNS was high, this was offset by the costs involved in nursing care and treating recurrent respiratory infections in those with mechanical ventilation, in addition to the indirect costs of home care, lost wages and quality- of- life.

\section{CONCLUSION}

Unilateral diaphragmatic pacing using a spinal cord stimulator to stimulate the phrenic nerve in the neck is a feasible option without significant complications in patients with $\mathrm{CNH}$. This is a viable alternative to prolonged continuous or intermittent ventilation for patients with persistent respiratory dysfunction due to stable neurological disorders.

\section{ACKNOWLEDGMENT}

The author would like to acknowledge the support of Mrs. Sunita for compiling the blood gas data and Mr. Atul Sood for technical inputs.

\section{REFERENCES}

1. Taira T, Hori T. Diaphragm pacing with a spinal cord stimulator: Current state and future directions. Acta Neurochir Suppl 2007;97:289-92.

2. Sitthinamsuwan B, Nunta-aree S. Phrenic nerve stimulation for diaphragmatic pacing in a patient with high cervical spinal cord injury. J Med Assoc Thai 2009;92:1691-5.

3. Glenn WW, Holcomb WG, McLaughlin AJ, O'Hare JM, Hogan JF, Yasuda R. Total ventilatory support in a quadriplegic patient with radiofrequency electrophrenic respiration. N Engl J Med 1972;286:513-6.

4. Khong P, Lazzaro A, Mobbs R. Phrenic nerve stimulation: The Australian experience. J Clin Neurosci 2010;17:205-8.

5. Le Pimpec-Barthes F, Gonzalez-Bermejo J, Hubsch JP, Duguet A, Morélot-Panzini $C$, Riquet $M$, et al. Intrathoracic phrenic pacing: A 10-year experience in France. J Thorac Cardiovasc Surg 2011;142:378-83.

6. Yasuma $\mathrm{F}$, Yasuura $\mathrm{K}$, Okamoto $\mathrm{H}$, Miyazaki M, Hirose $\mathrm{Y}$, Akune $\mathrm{K}$, et al. Clinical application of diaphragm pacing. J Thoracic Surg 1984;37:455-60.

7. Nannapaneni R, Behari S, Todd NV, Mendelow AD. Retracing “Ondine's curse". Neurosurgery 2005;57:354-63.

8. Onders RP, Dimarco AF, Ignagni AR, Aiyar H, Mortimer JT. Mapping the phrenic nerve motor point: The key to a successful laparoscopic diaphragm pacing system in the first human series. Surgery 2004;136:819-26.

9. Glenn WW, Phelps ML. Diaphragm pacing by electrical stimulation of the phrenic nerve. Neurosurgery 1985;17:974-84.

10. Hirschfeld S, Exner G, Luukkaala T, Baer GA. Mechanical ventilation or phrenic nerve stimulation for treatment of spinal cord injury-induced respiratory insufficiency. Spinal Cord 2008;46:738-42.

How to cite this article: Garg N. Unilateral phrenic nerve stimulation for neurogenic hypoventilation in Arnold Chiari malformation. Indian J Neurosurg 2013;2:284-7.

Source of Support: Nil, Conflict of Interest: None declared. 